\title{
Marta Chodkiewicz
}

Maria Curie-Skłodowska University, Pl. M. C. Skłodowskiej 5, 20-031 Lublin, Poland

\section{Undergraduate Students' Use of External Sources in Revising and Justifying Their Translation Decisions Based on Instructor Feedback}

\begin{abstract}
The article reports on a study conducted as part of a one-term undergraduate general translation course. In the final assignment the students delivered L1 and L2 translations which were assessed based on their functionality/usability and other criteria related to preserving the content of the source text and assuring the adequacy of the target text (ITI 2014). The students then worked on the problematic sections marked by the instructor; they could either revise the excerpts or justify their decisions. The students were allowed to make use of electronic sources, which was recorded using Camtasia Studio. The recordings were analysed to examine the types of searches the students had made.

Keywords: translator competence, translator training
\end{abstract}

\section{Introduction}

The competence related to being able to use technological tools and sources of information, primarily in order to conduct research in the translation process, is included in all of the most influential componential models of translation competence. In the PACTE model (2003) it is termed "instrumental sub-competence", while Göpferich 
(2009) labels it "tools and research competence". In these two models, this competence, similarly to the remaining sub-competences, is linked to the "strategic" sub-competence which is responsible for activating and regulating it, as well as to other sub-competences in the models. However, as postulated by PACTE (2000) and Kiraly (2013), novice translators tend to have weaker links between particular subcompetences and thus there is less interaction between them than in the case of professional translators. The difference in the extent to which expert and novice translators are able to control their subcompetences is shown in the models of the "broadband" (expert) and "narrow-band" (novice) translators developed by Alves and Gonçalves (2007: 50-52). In the latter the sub-competences, including the instrumental one, are disconnected from self-awareness and metacognition, which means that novices do not have proper control over this sub-competence. The EMT (2009) model, which constitutes a basis for EU-approved translation programmes, includes two competences which are related to carrying out research, namely "information mining competence" and, to some extent, "technological competence". The description of the first of them emphasises that sources should be used "effectively" and approached "critically" (EMT 2009: 6), which novices can be expected to have problems with based on the models discussed above and on the results of several studies which have shown that novices primarily use bilingual resources, often in an uncritical way (Barbosa and Neiva 2003, Faber 1998, Göpferich 2010, Krings 1986, Kussmaul 1995, Ronowicz et al. 2005).

Bearing in mind the training the participants of the study received in their sub-competence related to conducting research using information sources and tools, provided to all the students in the undergraduate programme, the aim of the current study was to investigate the students' use of external resources when revising and justifying their translation decisions, based on the instructor's feedback, in a special session held in class. The following research questions were posed: 
- To what extent will the students rely on external resources? (RQ1)

- What types of searches will the students make? (RQ2)

- What types of searching methods and resources need to be given more attention in training in this respect the future? (RQ3)

Additionally, the differences in external source use between students performing L1 and L2 translation were examined and some implications for course design were put forward.

\section{Method}

This section describes the method applied in the study, including its participants and setting, as well as the instruments and procedure used.

\subsection{Participants and setting}

The participants of the study were second-year students doing a BA programme in Applied Linguistics who specialise in translation. This was the year when the students started taking translation classes and most of them had no previous experience in translation. Some students who took part in the revision and justification session were excluded from the study in order to make the group as homogenous as possible, including students who had participated in exchange programmes and thus had not attended the classes at their home university and those whose mother tongue was not Polish. The revision processes of a total of 36 participants and the recordings of resource use by 34 of them were investigated in the study (two of the thirty-six students did not use external resources).

The study was conducted as part of a general translation class, which lasted one term. At the time of the study the students were taking the following translation classes in addition to the general translation class: a CAT tools class, a sight translation class, and a lecture in translation theory. The main goals of the general translation class were for the students to learn how to proceed in a strategic way (as understood by Göpferich 2011: 8) when translating. The students 
were to adopt a dynamic/functional approach towards translation (PACTE 2011b: 39), communicate with the client if necessary, and to use external resources critically and effectively ${ }^{1}$. Skills in revision and justification as well as in the critical and effective use of resources were trained during the course when discussing the assignments that the students had completed at home; the latter were also developed in a special session of the course, where sources other than bilingual dictionaries were focused on (see Chodkiewicz 2014a), and more extensively in the CAT tools class.

\subsection{Instrument}

The use of sources was investigated based on the recordings made using Camtasia Studio for 34 out of 36 participants who drew on external sources during the revision/justification session.

\subsection{Procedure}

In the final assignment in the course, which was the only graded assignment, the students translated one text individually at home using all available resources, and communicating with client if necessary. The texts were either in English (5) or in Polish (3), and the students were randomly assigned one of eight different texts. The English texts were the following: a household recycling guide, a brochure regarding fire safety, a text about being self-employed, an informal article concerning the consequences of eating fast food, and a brochure with information on health and safety. The Polish texts had to do with promoting Poland abroad, working for the Polish Post Office, and commuting to work in Poland. The texts posed a wide range of problems, including problems of comprehension and re-expression that were cultural, linguistic, intentional, textual (style, coherence, text type, etc.), and extralinguistic in nature, as well as problems related to the translation brief and target-text readers (PACTE 2011a).

\footnotetext{
${ }^{1}$ For a detailed description of the design of the course and students' perceptions of its selected aspects see Chodkiewicz (2014a, 2014b).
} 
The students' translations were then assessed by the instructor based on their functionality/usability, which is the focus of the course, as well as on other criteria (ITI 2014) ${ }^{2}$. These are related to preserving source text (ST) content (inaccurate transfer of content, additions, and omissions) and assuring target text (TT) adequacy (appropriate terminology, appropriate register/style, consistency, grammar/syntax, spelling, punctuation, layout, and coherence), with an additional designation "sense", when the target text is illogical and/or it could be incomprehensible for the reader. It is worth mentioning, however, that although only unjustified omissions, additions, and changes in content were marked in the previous editions of the course, in this particular case all of the deviations from the ST where an explanation was desirable were marked so as to elicit justification, which the students were made aware of. Problematic sections were marked using symbols denoting particular criteria, but no suggestions were made as to how to amend the texts.

The students then took part in a revision and justification session in class, during which they worked with their translations individually, either revising or justifying their decisions using a revision/justification sheet provided and quoting the sources if necessary. They were allowed to use electronic sources, which was recorded using screen-recording software (Camtasia Studio). The students were told that if considerable improvements were made, their grade for the assignment could be increased, which was to stimulate their motivation for completing the task. In another session the students were divided into groups according to the text they had translated. They examined the feedback they had received from the instructor on their corrections and they could compare their

\footnotetext{
${ }^{2}$ The idea to use ITI criteria and symbols representing them for assessment purposes in translation courses was originally presented to me by Beata Kaźmierczak (personal communication, 2010), who is a course tutor at the University of Surrey and ITI examiner.
} 
translations against the best translation of a given text produced by the students that year.

The screen recordings were analysed by the researcher, and the searches made by the participants were labelled and categorised (cf. the categorisation used in the comprehensive multiple case studies of web search behaviour by Enriquez Raido 2011 and Paradowska, forthcoming).

\section{Results and discussion}

The following sections present the results of the study with respect to the three research questions presented in the Introduction and their discussion.

3.1 Overall number and variety of searches

The first research question concerned the extent to which the students relied on external sources. Out of 36 participants qualified for the study, as many as 34 used external resources, and all the data presented in the remaining part of the article will concern this group only. The overall number and variety of searches made in the study (according to the classification presented in Section 3.2) differed to a large extent among the 34 participants who used sources, as shown in Figure 1. 


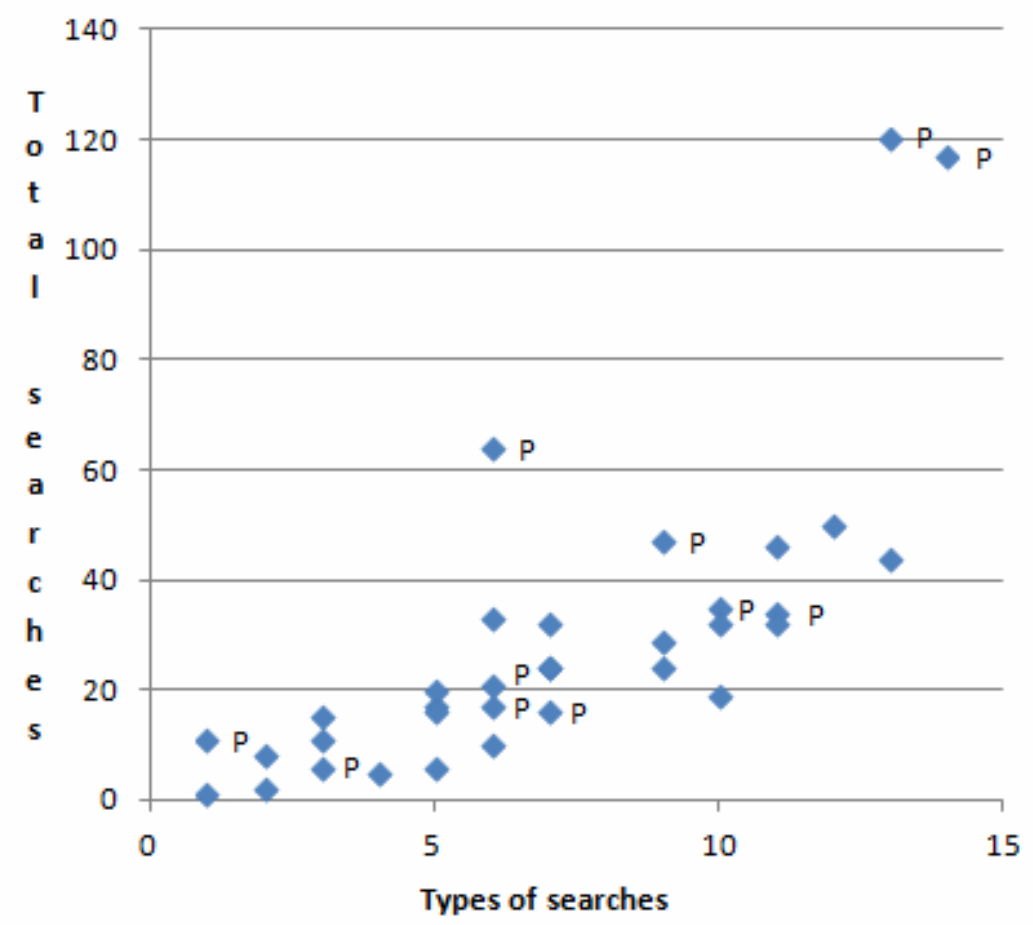

Figure 1. Total number and variety of searches (N=34; P - Polish text translated; no label - English text translated).

The smallest number of searches made was 1 and the greatest one was as high as 120 . The mean number of searches was 29.1 , with a high standard deviation (27.2); the median was 22.5 and the mode was 32 . As far as the variety of searches is concerned, the mean number of different types of searches conducted was 7 , with a much lower standard deviation (3.6), the median amounting to 6.5 and the mode to 6. As can be seen from Figure 1, the students who were translating out of their mother tongue made considerably more searches (mean $=44.4$ vs. 21.7 ; median $=34$ vs. $20 ;$ mode $=32$ for first group vs. no unique mode for the second one) and tended to rely on slightly more varied 
sources than those who did L1 translation (mean $=7.8$ vs. 6.7 ; median $=7$ vs. 6 ; mode $=6$ vs. 5 ). The increased number and variety of searches among students performing L2 translation may have been due to the fact that the students had made more errors when translating in this direction than those who had translated into their L1 (mean = 38.5 vs. 17 ; median $=43$ vs. 15 ; mode $=27.44$ vs. 15 ). Those students could have additionally been more hesitant to rely on internal resources, bearing in mind that their L2 competence is lower.

\subsection{Types of searches and their number}

The second research question concerned the types of searches the students made during the revision/justification session. Table 1 shows the abbreviations which were used in the Figures 2 and 3 to describe the searches, SL standing for "source language" and TL for "target language".

Table 1. Explanations for abbreviations used in Figure 2.

\begin{tabular}{|l|l|}
\hline Abbreviation & Explanation \\
\hline c__ & complex search performed using Google (tag) \\
\hline G T correct & Google query regarding TL correctness \\
\hline c_quot (2) & Google query with two terms in quotation marks \\
\hline c_eq & Google query with two equivalent terms \\
\hline EB search & $\begin{array}{l}\text { search in one of the two electronic bilingual dictionaries which } \\
\text { were provided (PWN-Oxford and New Kosciuszko Foundation } \\
\text { dictionaries) }\end{array}$ \\
\hline M (S) & $\begin{array}{l}\text { monolingual dictionaries (other than collocations dictionaries), } \\
\text { glossaries \& encyclopaedic dictionaries, other than Wikipedia } \\
\text { (SL) }\end{array}$ \\
\hline Colloc & English collocations dictionaries \\
\hline SynT & webpages with synonyms in TL \\
\hline Wiki+lg & Wikipedia + immediate language change \\
\hline Pz & term search on Proz.com \\
\hline Forum & fora other than Proz.com \\
\hline C+con & corpus search for concordances (National Corpus of Polish); no \\
\hline
\end{tabular}

${ }^{3}$ These are advanced searches in Google, which mostly correspond with Enriquez Raido's (2011) classification of complex queries. 


\begin{tabular}{|l|l|}
\hline C+coll & special setting used \\
\hline Eur-lex bd & $\begin{array}{l}\text { corpus search for collocates (National Corpus of Polish), with } \\
\text { setting adjustment }\end{array}$ \\
\hline Eur-lex SS & Eur-lex bilingual display \\
\hline Eur-lex O & Eur-lex simple search \\
\hline PS & Eur-lex other action \\
\hline PT & SL text (similar text type) \\
\hline+ CtrlF & TL text (similar text type) \\
\hline
\end{tabular}

Figures 2 and 3 below show the results for the all of the searches and for the less common ones, respectively. 


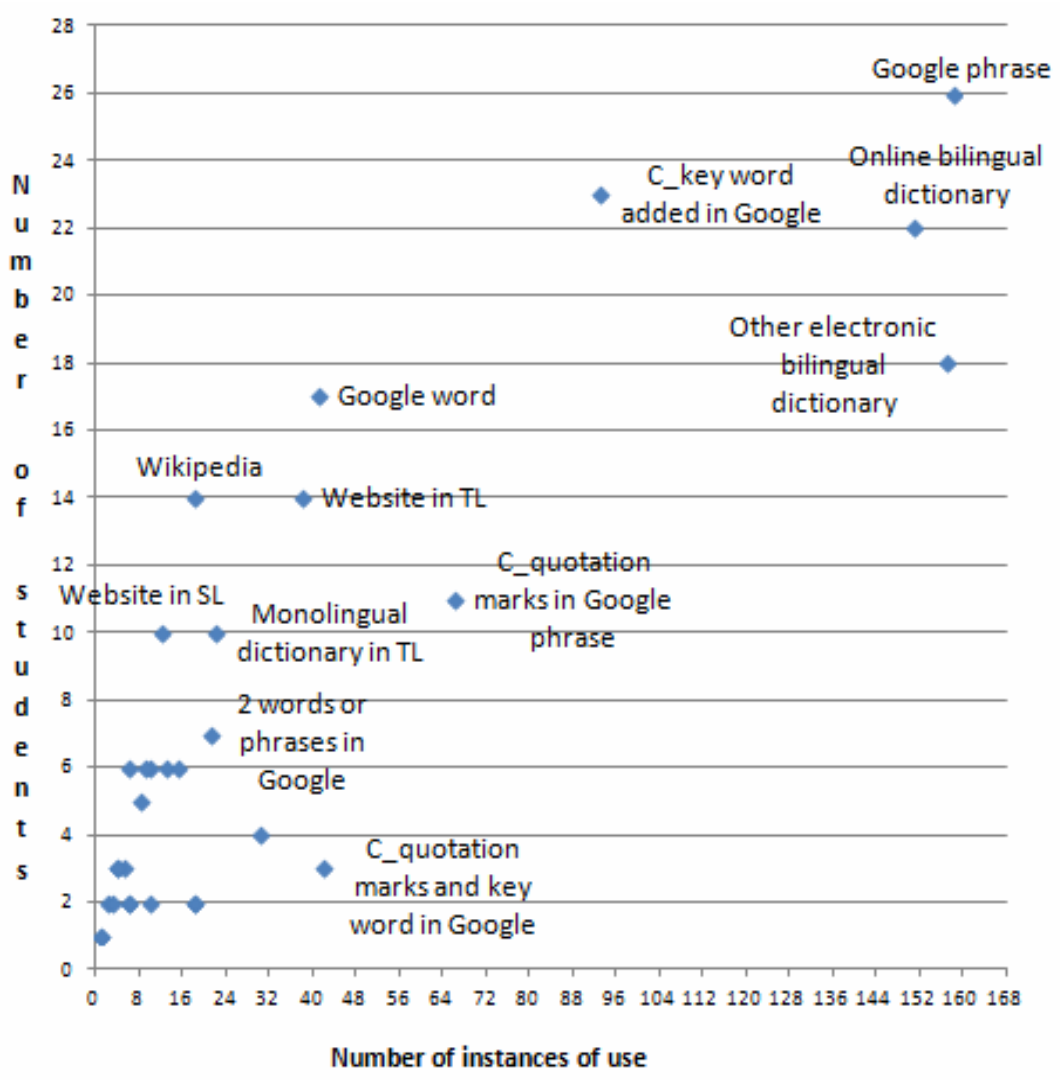

Figure 2. Number of particular types of searches performed by the students: all searches $(\mathrm{N}=34)$. 


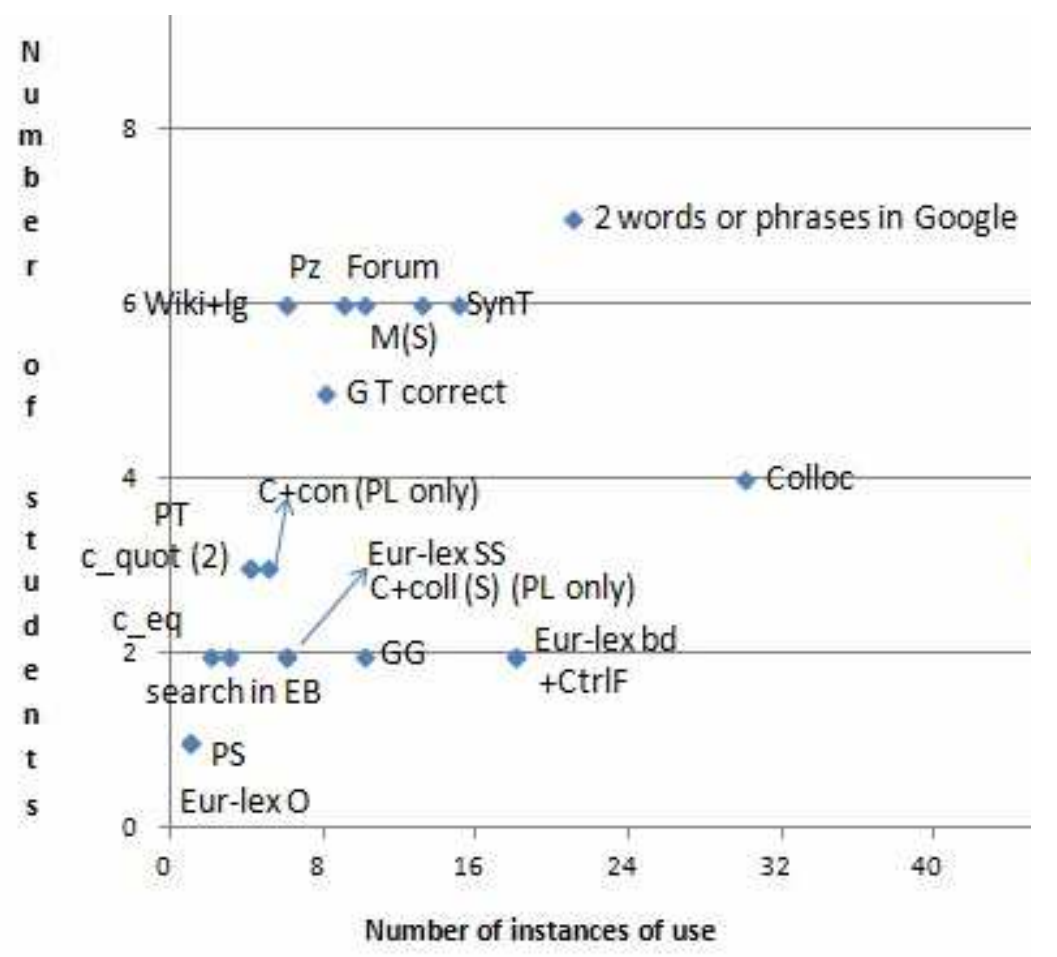

Figure 3. Number of particular types of searches performed by the students: least frequent searches $(\mathrm{N}=34)$

As can be seen in Figure 2, the most common search made by the students was googling a phrase without quotation marks, in which case the search engine displays pages with all of the terms entered. However, there were many cases when it was clear that using quotation marks to obtain the results for a phrase would have been more useful, and yet the students used this type of complex search much less often. On the other hand, as many as 23 students conducted a highly useful and flexible complex search involving a key word used in a Google query, and 3 used both a key word and quotation marks in their query. This search can be very effective as Google may display 
pertinent results from several different sources of the same type (when "dictionary", "translation", "English", or "synonym" are added), without the user having to go to each potential source individually, or take the user to a particular source (e.g. "Eur-lex", "proz", "freedictionary"). Apart from the terms mentioned in brackets, the students would also add very precise terms such as "budowa" ("structure") to efficiently look for webpages describing the structure of a physical object, or phrases such as "what does it mean", which could take them to a forum answering this question, as well as sources such as Wikipedia and dictionaries. The students also made particularly extensive use of bilingual dictionaries, both online dictionaries of their choice (22) of the electronic dictionaries provided (18). However, only very few of them (2) were successful in searching within the entries in the electronic dictionaries, where the "Control Find" command did not work; as a result, in some cases the students had to spend a substantial amount of time looking though the entry. Although it may be understandable that in this particular situation the students did not want to spend much time learning how such a search may be performed in the dictionaries, for instance by consulting the "Help" section or hovering over the available options, proceeding in such a way when regularly working with a particular source is very inefficient.

Other common searches included searching for individual words, which is the simplest query possible in Google, and going to websites in the target and source languages, which did not contain parallel texts representing the same text type. Fourteen students consulted websites in the TL in the revision phase. It seems they did so mostly to clear up doubts as to word usage and the precise meaning of certain words, as there were several problems with accurate transfer of content and terminology in their work. The websites were either related thematically to the source texts or delivered explanations as to TL correctness. It might be surprising that in the revision phase as many as 10 students consulted websites in the SL, but, as already mentioned, the students needed to correct several errors to do with meaning, so they needed to make sure they knew the correct meaning of certain 
items in the source language as well as the target language. The students probably often referred to monolingual dictionaries in both the source (6) and target languages (10) for similar reasons.

Another source which was drawn on to find both extra-linguistic and terminological information was Wikipedia. It was consulted by 14 students in a monolingual version. Similarly to the other sources mentioned above, some of the students utilised Wikipedia to gain extralinguistic or encyclopaedic knowledge instead of limiting themselves to searching for the terms only; the importance of gaining such knowledge had been emphasised in class. Six students used Wikipedia with an immediate change in the language, which suggests rather a terminological focus. This is an efficient way to check terms from different domains and can be used as a good alternative to consulting other bilingual sources, such as dictionaries. The same number of students (6) consulted each of the following sources: Proz, other fora (including those having to do with TL correctness), and webpages with synonyms in the TL, which might have been particularly helpful when dealing with stylistic problems. Five students made queries to do with TL correctness, which could lead to their question being answered in Google suggestions or to them being provided with a list of websites that they could then examine or go to.

Yet another useful source of terminological information, though used by few students, as can be seen in Figure 3, was Google graphics, which was not formally presented during any of the courses. The students relied on it when dealing with physical objects and sometimes compared the results for two equivalent terms, which is a fast and efficient way of making sure the terms refer to the same object. Another way of formulating Google queries which the students were not introduced to formally was googling two equivalents of the same word. Only two students formulated their queries this way, but this can be an efficient way to access bilingual websites.

The remaining sources which the students did not draw on very often, as can be seen in Figure 3, include Eur-lex, English collocations dictionaries, the Polish National Corpus (with the adjustment of setting in the collocates search), and parallel texts. It is possible that 
the students had used these sources in the translation phase and that is why they did not draw on them in the revision phase. Still another reason could be that the students did not find these sources useful for dealing with the texts they had translated in the assignment. However, it may also have been the case that they are did not feel confident about using them.

It seems even more surprising that none of the students relied on corpora of the English language, such as the BYU-BNC or COCA, despite the fact that 11 out of 34 students translated texts into English and there were situations when these sources could have been clearly helpful. Another issue is that as few as 2 students made use of the $\mathrm{Ctrl}+\mathrm{F}$ command. This command was not given particular emphasis in class, but was mentioned when discussing browsing through the bilingual display in Eur-lex in class, and the two students who used it applied it with Eur-lex. Not using this command often made the searches much more time-consuming.

4. Conclusions and practical implications

An overwhelming number of students who were qualified for the study (94\%) used external sources when revising and justifying their decisions, carrying out 29.1 searches and 7 various types of searches, according to the classification used in the study, on average (mean). The students who performed L2 translation relied more heavily on a divers types of searchers, which may have been due to the greater number of errors in their work compared to that in the work of L1 translators and/or lack of confidence in their L2 competence. The most common searches included various types of bilingual sources, among others dictionaries, websites, Wikipedia, and fora, as well as different types of Google queries, with complex queries involving key words specifying the type of information or source being sought ranking high. The students performed searches related to both comprehension and re-expression problems, conducting research related not only to the equivalents of particular terms, but also to word meaning, extralinguistic knowledge, and TL correctness. 
The findings of the study helped identify some types of searches which were used the least frequently by the students, although the reason why it was so remains unclear, and also searches which were performed by several students, but are useful to the extent that they are worth discussing in class (see the last point in the list below). Based on the results of study, it seems that the use of the following sources in particular need to be paid attention to or emphasised more in the next editions of the courses offered to undergraduate students specialising in translation (to answer the third research question):

- the "Control Find" command,

- quotation marks to search for an entire phrase,

- English language corpora,

- Google graphics to make sure correct terms for physical object were chosen,

- the search function in electronic dictionaries not available online,

- queries consisting of SL \& TL equivalents,

- queries containing key words.

Undoubtedly, there is a need to discuss the use of external sources more extensively and for a given situation, which had not been done in class to a great extent before the study was conducted; nor was this problem addressed in the current study. In the current edition of the course not only are the students' research skills trained more thoroughly, but they are also assessed, as the students comment on their use of external resources in the translation process in special retrospective questionnaires that they complete for almost every translation task during the course. Moreover, they analyse their own collaborative translation processes, including assessing the strategicness of source use and suggesting improvements. Such process-based methods allow for a detailed and contextualised discussion and reflection regarding resource use both in the translation and revision phases of the translation process. 
Note

The study was financed by the Polish Ministry of Science and Higher Education (grant number 42/2014 awarded by Maria Curie-Skłodowska University in Lublin).

\section{References}

Alves, F. and Gonçalves, J. L. 2007. Modelling translator's competence: relevance and expertise under scrutiny. In: Y. Gambier, M. Shlesinger and R. Stolze (eds) Translation studies: doubts and directions. Amsterdam: John Benjamins. 41-55.

Barbosa, H. G. and Neiva, A. M. 2003. Using think-aloud protocols to investigate the translation process of foreign language learners and experienced translators. In F. Alves (ed.) Triangulating translation: perspectives in process-oriented research. Amsterdam, John Benjamins. 137-55.

Chodkiewicz M. 2014a. Addressing the challenges of designing a general translation course for undergraduate students. In: M. Piotrowska and S. Tyupa (eds) Intralinea, Special issue, Challenges in translation pedagogy. (available at http://www.intralinea.org/specials/article/the challenges of designing a general translation course for undergraduates )

Chodkiewicz M. 2014b. Student perceptions of the usefulness and effectiveness of a basic course in translation simulating working with a client. In: K. Uzule (ed.) Multidimensional translation: from science to arts. Riga: Baltic International Academy. 244-254.

Enriquez Raido, V. 2011. Investigating the web search behaviors of translation students: an exploratory and multiple-case study. Unpublished PhD dissertation. Universitat Ramon Llull: Barcelona. (available at http://www.tesisenred.net/bitstream/handle/10803/21793/Enriquez_PhD_Thesis_ Final.pdf?sequence $=1$ )

EMT. 2009. Competences for professional translators, experts in multilingual and multimedia communication. (available http://ec.europa.eu/dgs/translation/programmes/emt/key_documents/emt_compete nces_translators_en.pdf)

Faber, P. 1998. Translation competence and language awareness. In: Language Awareness 7 (1). 9-21.

Göpferich, S. 2009. Towards a model of translation competence and its acquisition: The longitudinal study 'TransComp'. In: S. Göpferich, A. L. Jakobsen and I. M. Mees (eds) Behind the mind: methods, models and results in translation process research (Copenhagen Studies in Language 37). Copenhagen: Samfundslitteratur. 11-37.

Göpferich, S. 2010. The translation of instructive texts from a cognitive perspective. In: S. Göpferich, A. L. Jakobsen and I. M. Mees (eds) New approaches in 
translation process research (Copenhagen Studies in Language 39). Copenhagen: Samfundslitteratur. 5-55.

Göpferich, S. 2011. From multidisciplinarity to transdisciplinarity: the investigation of competence development as a case in point. MikaEL electronic proceedings of the KäTu Symposium on Translation and Interpreting Studies 5. 1-24. (available at: http://www.sktl.fi/@Bin/85366/Gopferich_MikaEL2011.pdf )

ITI, Institute of Translation and Interpreting. 2014. Exam guide. (available at: http://www.iti.org.uk/attachments/article/357/Exam\%20Guide\%202014.pdf )

Kiraly, D. 2013. Towards a view of translator competence as an emergent phenomenon: thinking outside the box(es) in translator education”. In: D. Kiraly, S. Hansen-Schirra and K. Maksymski (eds) New prospects and perspectives for educating language mediators. Tübingen: Gunter Narr. 197-224.

Krings, H. P. 1986. Translation problems and translation strategies of advanced German learners of French (L2). In: J. House and S. Blum-Kulka (eds) Interlingual and intercultural communication. Discourse and cognition in translation and second language acquisition studies. Tübingen: Gunter Narr. 263276.

Kussmaul, P. 1995. Training the Translator. Amsterdam: John Benjamins.

New Kosciuszko Foundation Dictionary. 2003. Kraków: Towarzystwo Autorów i Wydawców Prac Naukowych Universitas.

PACTE. 2000. Acquiring translation competence: hypotheses and methodological problems in a research project. In: A. Beeby, D. Ensinger and M. Presas (eds) Investigating Translation. Selected Papers from the 4th International Congress on Translation, Universitat Autònoma de Barcelona, 1998. Amsterdam: John Benjamins. 99-106.

PACTE. 2003. Building a translation competence model. In: F. Alves (ed.) Triangulating translation: perspectives in process oriented research. Amsterdam: John Benjamins. 43-66.

PACTE. 2011a. Results of the validation of the PACTE translation competence model: translation problems and translation competence. In: C. Alvstad, A. Hild and E. Tiselius (eds) Methods and strategies of process research: integrative approaches in translation Studies. Amsterdam: John Benjamins, 317-343.

PACTE. 2011b. Results of the validation of the PACTE translation competence model: translation project and dynamic translation index. In: S. O'Brien (ed.) Cognitive explorations of translation. London: Continuum Studies in Translation. 30-53.

Paradowska, U. 2015. Expert web searching skills for translators â “ a multiple-case study. In: P. Pietrzak and M. Deckert (eds) Constructing translation competence. Frankfurt am Main: Peter Lang, 227-244. 
PWN-Oxford Dictionary (Wielki multimedialny słownik angielsko-polski polskoangielski PWN-Oxford). 2011. Warszawa: Wydawnictwo Naukowe PWN.

Ronowicz, E., Hehir, J., Kaimi, T., Kojima, K., Deok-shin L. 2005. Translator's frequent lexis store and dictionary use as factors in SLT comprehension and translation speed - a comparative study of professional, paraprofessional and novice translators. In: Meta 50 (2). 580-596. 